\title{
含クロム白銑の黑鉛化に及法す各種合金元素の影響に就いて
}

(昭利 27 年 4 月本會潇演大會にて嚇演)

\author{
堤信 久 \\ EFFECT OF ALLOYING ELEMENTS ON GRAPHITIZATION \\ OF A WHITE IRON CONTAINING SMALL PER CENT OF CHROMIUM
}

Nobuhisa Tsutsumi

Synopsis:

It had been known for many years in malleable foundries that small amounts of chromium having the retarding effect on the graphitization of ordinary black heart malleable iron both in the first and second stage anpealing, especially on the latter. No research, however, with effective results to neutralize the retarding effect of chromium on annealing rate haá been done. In view of the fact that manganese having strong affinity with sulphur neutralized the strong retarding effect of sulphur by forming manganese sulphide, if there were soms alloying elements having strong affinity with chromium were investigated. As no detailed publication on the affinity among elements had been described, however, the auhors' researehes were dircted towards to invegtigate effects of 21 alloying elements on graphitization of the white iron containing $0 \cdot 156 \%$ of chromium.

Results obtained were summarized as follows:

1) The ferrite matrix which was characteristic of malleable iron did not appear in the most specimens without containing boron; aluminium, silicon and $0.2 \%$ titanium and copper above $2 \cdot 0$ per cent. 2) Better results were obtained by adding aluminium, silicon, titanium, copper, boron and zirconium which had been known as strong deoxydizers. It had not yet been made clear however, if there were close relation between the better effect of above mentioned alloying elements in graphitization and the retarding effect of chromium.

It was concluded that there was no strong graphitizer by which was neutratized the retarding effect of chromium as in order of $0.156 \%$ per cent content in the present research fleld.

\section{I. 绪言之研究目的}

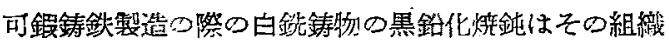
老焙戻炭素と完全なフェライト地にするため，実際操業

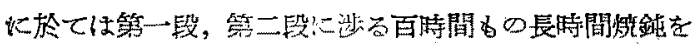

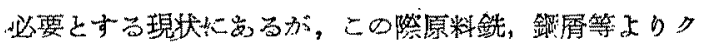
口ム元素が不鉡分として $0 \cdot 1$ - $0 \cdot 15 \%$ 程度混入すれば

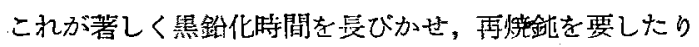
或は全く焼䥫不能とさえなること多く发る。このよう

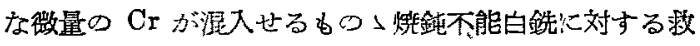

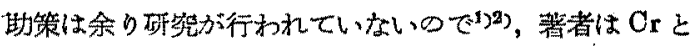

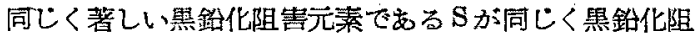

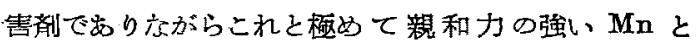

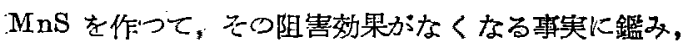

$\mathrm{Cr}$ と親和力の強いう寈を見付ける目的にて各種で菜の

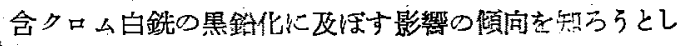
たのである，クロ太を合まない白銑の黑鉛化に及ぼす諸

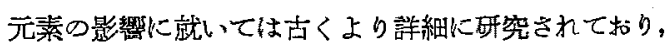
H. A. Schwartzis), E. Schüz), R. Stotzy, P. Ober-

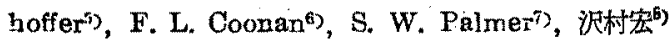

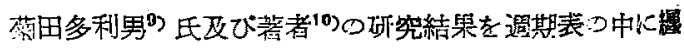
やれば第1图の如くなる.図中一元素に就き異分記号を 併記するbのは研究者により異つた結啉が出ているもの

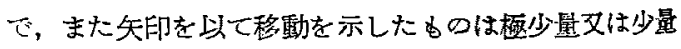

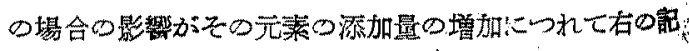
呂に变化することを示したるのである。遇期表に於いて

* 早稻田大學路物研究所 


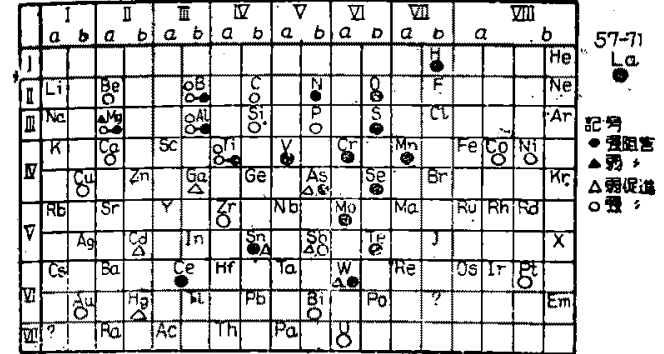

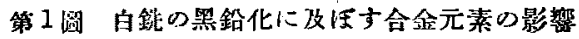

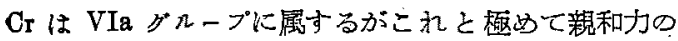
强い元素に就いての文献は詳細なるのがないので, 比較

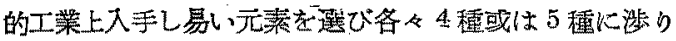
その添加量を变化させて21 元菜 86 種口源加量と就い てその含クロム白銑の黒鉛化を謂心た。

\section{II. 實 驗 方 法}

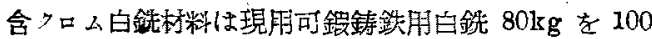
$\mathrm{kg}$ 容量高周波䔻導户にて焠解し，これにフェロクロム (Cr 63.81\%) を添加して，現場にては普通焙鉝不能と 言われる Or 量 0.156\% を含有せし的第1表の如き化 学組成の白銑を製造した。

第1表 含ク口ム白銑の化學組成

\begin{tabular}{c|c|c|c|c|c|c}
\hline 氞料記號 & $\mathrm{C} \%$ & $\mathrm{Si} \%$ & $\mathrm{Mn} \%$ & $\mathrm{P} \%$ & $\mathrm{~S} \%$ & $\mathrm{Cr} \%$ \\
\hline $\mathrm{CR}$ & 2.74 & $\mathbf{1 . 1 9}$ & $\mathbf{0 . 2 5}$ & 0.095 & 0.075 & 0.156 \\
\hline
\end{tabular}

これを原料としてクリプトれ電気提折师を用いて黒鈶 㘫佩中で $700 \mathrm{~g}$ 宛综解し，これに夫々 $\mathrm{Na}, \mathrm{Cu}, \mathrm{Mg}$, $\mathrm{Zn}, \mathrm{Cb}, \mathrm{B}, \mathrm{Al}, \mathrm{Si}, \mathrm{Ti}, \mathrm{Zr}, \mathrm{Sn}, \mathrm{Pb}, \mathrm{P}, \mathrm{V}, \mathrm{Sb}, \mathrm{Bi} \mathrm{S}$,

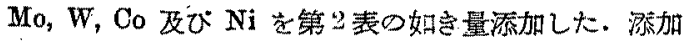
方洪としては沸点の低い元素 $\mathrm{Na}\left(925^{\circ} \mathrm{C}\right), \mathrm{Mg}\left(1107^{\circ} \mathrm{C}\right)$ $\mathrm{Zn}\left(907^{\circ} \mathrm{C}\right)$ 及び $\mathrm{Cd}\left(767^{\circ} \mathrm{C}\right)$ 源加の埸合は师外て源加

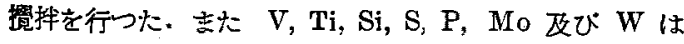
純金属を用いず，夫々 $\mathrm{Fe}-\mathrm{V}(40 \% \mathrm{~V}), \mathrm{Fe}-\mathrm{Ti}(27 \cdot 0 \% \mathrm{Ti})$ $\mathrm{Fe}-\mathrm{Si}(81 \cdot 33 \% \mathrm{Si}), \mathrm{Fe}-\mathrm{S}(36 \cdot 5 \% \mathrm{~S}), \mathrm{FeP}(20 \cdot 03 \% \mathrm{P})$ $\mathrm{Fe}-\mathrm{Mo}(40 \cdot 2 \% \mathrm{Mo}), \mathrm{Fe}-\mathrm{W}(51 \cdot 0 \% \mathrm{~W})$ \%鉄合金老用い て源加した．源加の際は添加歩留を等虚儿入れて添加量

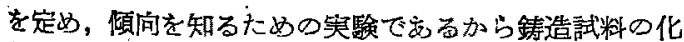
学分折は行わながた．炉中で港加を行つたすのは塔湯 中の偏析及び接種新果を避ける目的で $5 \mathrm{~min}$ 保持して 後 $10 \mathrm{~mm}$ 直径 $150 \mathrm{~mm}$ 舆口丸棒を生型鋳込双した。台 比較のため合金元素添加を行わない試料も再揢解鋳造し た.

遊離セメンタイト照鈶化のための保持温度としては $930^{\circ} \mathrm{C}$ を選び，各試料を $20 \mathrm{~mm}$ 長さにグラインダー切 断し一筀に 87 本宛入れ $15 ， 25 ， 30 ， 35 ， 40$ 及び 45 時間焼鈍し，灯の操作上 $600^{\circ} \mathrm{O}$ 迄炉冷後開屝し試料を 取出して空冷後頙微箕下にてセメンタイトの残留の有無 及び程度を検查した４5時間にても冏残存するものに 就いては更らに別に绐めから $50,55 ， 60$ 時間焼釛を行 つた. また共析せメンタイトの黒鉛化温度は，各試料の

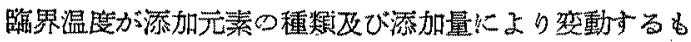
のであるが，実駼の都合上本研究では $720^{\circ} \mathrm{C}$ 一定に定 めて $15,35,95,115,145,165,200$ 時間孛順次に行 つた.この第二段拯䤞は所要特間後 $10 \mathrm{~mm}$ 長さ宛切落 して残りにつき次の焼鈍を行つた．各㭙間の焟鈍を終え

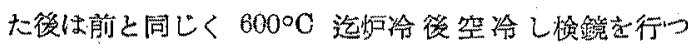

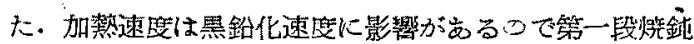
温度 $930^{\circ} \mathrm{C}$ 迄は $2.5 \mathrm{hr}$ ，第二段烧鈃温度 $7200^{\circ} \mathrm{C}$ 迄は ー1 hr一定となるようにした。また微量のたメンタイト

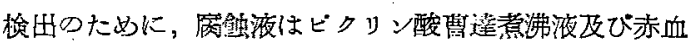
塩加里溶液 (赤血塩 $3 \mathrm{~g}$, 䔩性加里 $10 \mathrm{~g}$, 水 10 c.c. $65^{\circ} \mathrm{C} \sim$ $70^{\circ} \mathrm{O}$ て應蝕〉を朋い。

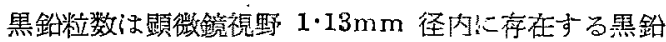

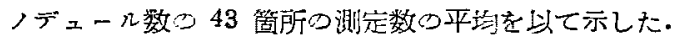
また绻戻岸素の大ききは同しく 9 視野儿就いて稌镜し各 視野にて最も頻度数の大なる大きさの数字な数にこ 3 個亚 ベて見脚けの大きさを示した。例党ば Ti $0.02 \%$ 添加 した OR1071 の燃㞔炭素の大きさの测定值は第2表の 通りで (5・5・4)を以て表示する。

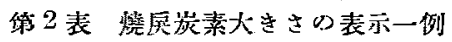

\begin{tabular}{|c|c|c|c|c|c|}
\hline \multicolumn{2}{|c|}{ CR1071 } & \multicolumn{2}{|c|}{ (Ti $0.02 \%$ 添加) } & た & きさ $\mid 5 \cdot 5 \cdot 4$ \\
\hline 湘 & 䘽野 1 & $\begin{array}{l}5 \times 5 \\
7 \text { 個 }\end{array}$ & $3 \times \frac{2}{4 \text { 個 }}$ & $\begin{array}{r}2 \times 2 \\
4 \text { 佪 }\end{array}$ & \\
\hline 定 & 2 & $\begin{array}{l}8 \times 7 \\
. \text { 個 }\end{array}$ & $\begin{array}{r}5 \times 4 \\
8 \text { 個 }\end{array}$ & $\begin{array}{r}3 \times 3 \\
4 \text { 蔨 }\end{array}$ & $2 \times 2$ \\
\hline 值 & 3 & $\begin{array}{l}4 \times 4 \\
8 \text { 個 }\end{array}$ & $\begin{array}{r}3 \times 3 \\
5 \text { 個 }\end{array}$ & $\begin{array}{c}2 \times 2 \\
5 \text { 個 }\end{array}$ & $\begin{array}{c}2 \times 2 \\
1 \text { 個 }\end{array}$ \\
\hline
\end{tabular}

單位: $0.0128 \mathrm{~mm}$

\section{，III. 實驗結果とその考察}

第 3 表には $930^{\circ} \mathrm{C}$ に於ける遊路七メンタイトの第一 段黑鈶化完了時間，72000 に於ける共析七メンタイトの 第二段黒鈶化完了時間，或は第二段黒鉛化の完了せ奴も のK就いては $200 \mathrm{hr}$ 蛢鈍終了㭙のバーライト組織の状

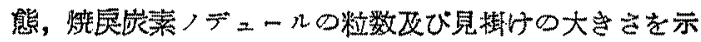
した.

第一段黒鈶化持間に欧はす合金元素添加の影得を第 2 図 に，第二段黑鉛化に及改す影響を第 4 表に共々示した。 


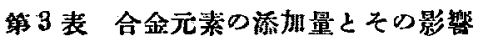

\begin{tabular}{|c|c|c|c|c|c|c|c|}
\hline 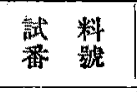 & 添加 & $\begin{array}{c}\text { 添加 } \\
\%\end{array}$ & $\begin{array}{l}\text { 第一段 } \\
\text { 黑铅化 } \\
\text { 時間 hr }\end{array}$ & 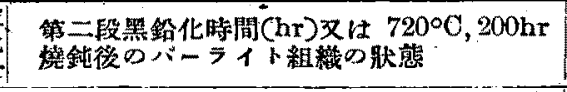 & 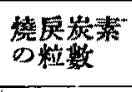 & 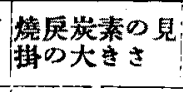 & 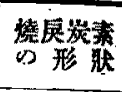 \\
\hline C R 1022 & サシ & -- & 45 & 200hr にて粒狀バーライト多し & $11 \cdot 3$ & $5 \cdot 5 \cdot 4$ & 塊 \\
\hline $\begin{array}{l}\mathrm{C} R 1231 \\
\mathrm{C} R 1232 \\
\mathrm{C} R 1233 \\
\mathrm{C} R 1234\end{array}$ & $\mathrm{Na}$ & $\begin{array}{l}0 \cdot 016 \\
0 \cdot 04 \\
0 \cdot 12 \\
0 \cdot 30\end{array}$ & $\begin{array}{l}40 \\
40 \\
35 \\
35\end{array}$ & $\begin{array}{l}\text { 粒狀パーライト } \\
\text { 粒狀ハーライト多し } \\
\text { 同 } \\
\text { 同 }\end{array}$ & $\begin{array}{l}12 \cdot 0 \\
15 \cdot 1 \\
18 \cdot 1 \\
16 \cdot 1\end{array}$ & $\begin{array}{l}6 \cdot 5 \cdot 4 \\
8 \cdot 7 \cdot 7 \\
7 \cdot 6 \cdot 6 \\
7 \cdot 6 \cdot 5\end{array}$ & $\begin{array}{l}\text { 塊 } \\
\text { " } \\
" 1\end{array}$ \\
\hline $\begin{array}{l}\text { C R 1081 } \\
\text { C R } 1082 \\
\text { C R } 1083 \\
\text { C R } 1084 \\
\text { O R } 1085\end{array}$ & $\mathrm{Cu}$ & $\begin{array}{l}0 \cdot 2 \\
0 \cdot 5 \\
1 \cdot 0 \\
1 \cdot 5 \\
2 \cdot 0\end{array}$ & $\begin{array}{l}40 \\
35 \\
35 \\
35 \\
35\end{array}$ & 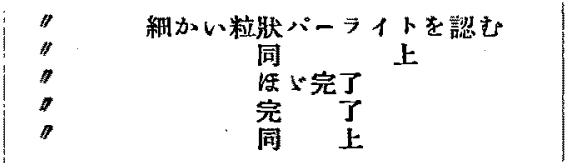 & $\begin{array}{l}15 \cdot 2 \\
16 \cdot 6 \\
17 \cdot 6 \\
17 \cdot 2 \\
20 \cdot 2\end{array}$ & $\begin{array}{l}6 \cdot 5 \cdot 4 \\
4 \cdot 3 \cdot 2 \\
5 \cdot 4 \cdot 4 \\
4 \cdot 3 \cdot 2 \\
4 \cdot 3 \cdot 3\end{array}$ & 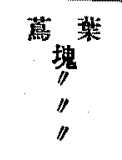 \\
\hline $\begin{array}{l}\mathrm{CR} R 161 \\
\mathrm{C} \operatorname{R} 1162 \\
\mathrm{CR} \operatorname{R} 163 \\
\mathrm{CR} 1164\end{array}$ & $\mathrm{Mg}$ & $\begin{array}{l}0 \cdot 2 \\
0 \cdot 5 \\
1 \cdot 0 \\
1 \cdot 5\end{array}$ & $\begin{array}{l}45 \\
40 \\
40 \\
40\end{array}$ & 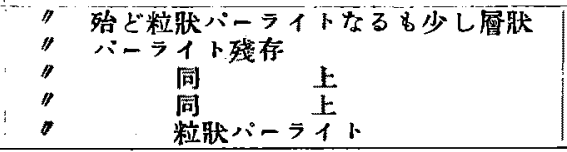 & $\begin{array}{l}31 \cdot 8 \\
20 \cdot 3 \\
23 \cdot 2 \\
16 \cdot 3\end{array}$ & $\begin{array}{l}2 \cdot 2 \cdot 1 \\
2 \cdot 3 \cdot 1 \\
3 \cdot 3 \cdot 2 \\
4 \cdot 4 \cdot 3\end{array}$ & $\begin{array}{c}\text { 球 } \\
\text { 球狀的塊 } \\
\text { 㻑 } \\
\text { 塊 }\end{array}$ \\
\hline $\begin{array}{l}\text { C R1101 } \\
\text { C R } 1102 \\
C R 1103 \\
C R 1104\end{array}$ & $Z_{n}$ & $\begin{array}{l}0 \cdot 1 \\
0 \cdot 3 \\
0 \cdot 5 \\
0 \cdot 7\end{array}$ & $\begin{array}{l}45 \\
40 \\
40 \\
45\end{array}$ & 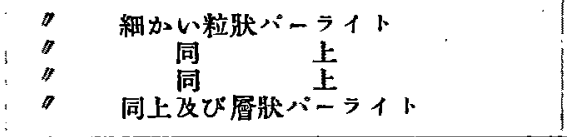 & $\begin{array}{l}17 \cdot 4 \\
19 \cdot 3 \\
22 \cdot 1 \\
38 \cdot 1\end{array}$ & $\begin{array}{l}5 \cdot 4 \cdot 4 \\
4 \cdot 3 \cdot 4 \\
4 \cdot 3 \cdot 4 \\
4 \cdot 5 \cdot 3\end{array}$ & 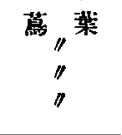 \\
\hline $\begin{array}{l}\text { O R R I181 } \\
\text { C R } 1182 \\
\text { C R II83 } \\
\text { C R } 1184\end{array}$ & $\mathrm{Cd}$ & $\begin{array}{l}0 \cdot 05 \\
0 \cdot 10 \\
0 \cdot 30 \\
0 \cdot 50\end{array}$ & $\begin{array}{l}45 \\
40 \\
35 \\
35\end{array}$ & 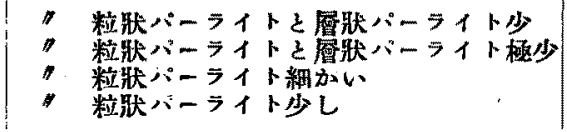 & $\begin{array}{l}10 \cdot 2 \\
11 \cdot 4 \\
17 \cdot 3 \\
21 \cdot 6\end{array}$ & $\begin{array}{l}5 \cdot 5 \cdot 4 \\
5 \cdot 5.3 \\
4 \cdot 5 \cdot 3 \\
3 \cdot 4.3\end{array}$ & 塊 \\
\hline $\begin{array}{l}\text { C R } 1031 \\
\text { C R } 1032\end{array}$ & $B$ & $\begin{array}{l}0 \cdot 016 \\
0 \cdot 028\end{array}$ & $\begin{array}{l}45 \\
50\end{array}$ & $\begin{array}{l}\text { 145hr 完了 } \\
\text { 同 }\end{array}$ & $\begin{array}{l}73 \cdot 1 \\
90 \cdot 9\end{array}$ & $\begin{array}{l}1 \cdot 2 \cdot 2 \\
1 \cdot 1 \cdot 2\end{array}$ & 粒 \\
\hline $\begin{array}{l}\text { O R } 1041 \\
\text { C R } 1042 \\
\text { C R } 1043 \\
\text { C R } 1044 \\
\text { C R } 1045\end{array}$ & Al & $\begin{array}{l}0 \cdot 05 \\
0 \cdot 10 \\
0 \cdot 20 \\
0 \cdot 30 \\
0 \cdot 40\end{array}$ & $\begin{array}{l}40 \\
40 \\
35 \\
35 \\
40\end{array}$ & 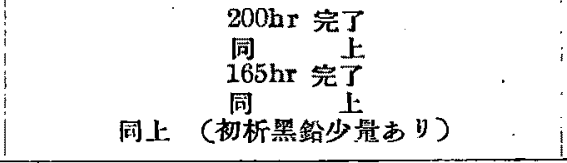 & $\begin{array}{l}18 \cdot 3 \\
15 \cdot 4 \\
23 \cdot 1 \\
24 \cdot 3 \\
36 \cdot 6\end{array}$ & $\begin{array}{l}4 \cdot 4 \cdot 2 \\
3 \cdot 4 \cdot 3 \\
2 \cdot 3 \cdot 3 \\
2 \cdot 2 \cdot 3 \\
2 \cdot 3 \cdot 3\end{array}$ & 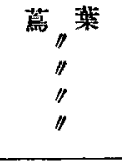 \\
\hline $\begin{array}{l}\text { C R } 1131 \\
\text { C R } 1132 \\
\text { C R } 1133 \\
\text { O R } 1134\end{array}$ & Si & $\begin{array}{l}0 \cdot 05 \\
0 \cdot 10 \\
0 \cdot 15 \\
0 \cdot 20\end{array}$ & $\begin{array}{l}45 \\
45 \\
35 \\
35\end{array}$ & $\begin{array}{l}200 \mathrm{hr} \text { 玨 ド完了 } \\
\text { 同 } \\
\text { 同 } \\
200 \mathrm{hr} \text { 完了 }\end{array}$ & $\begin{array}{l}10 \cdot 7 \\
13 \cdot 7 \\
1.6 \cdot 4 \\
21 \cdot 2\end{array}$ & $\begin{array}{l}5 \cdot 3 \cdot 4 \\
5 \cdot 4 \cdot 4 \\
5 \cdot 4 \cdot 3 \\
4 \cdot 4 \cdot 4\end{array}$ & $\begin{array}{l}\text { 塊 } \\
" \prime \\
" \prime\end{array}$ \\
\hline $\begin{array}{l}\text { C R } 1071 \\
\text { C R } 1072 \\
\text { C R } 1073 \\
\text { C R } 1074 \\
\text { C R } 1075\end{array}$ & $\mathbf{T i}$ & $\begin{array}{l}0 \cdot 02 \\
0 \cdot 05 \\
0 \cdot 10 \\
0 \cdot 20 \\
0 \cdot 50\end{array}$ & $\begin{array}{l}45 \\
45 \\
35 \\
35 \\
40\end{array}$ & 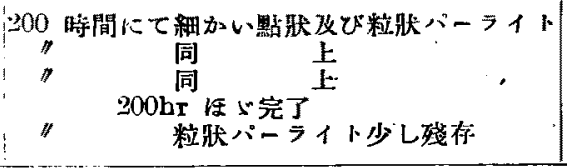 & $\begin{array}{l}16 \cdot 4 \\
19 \cdot 4 \\
19 \cdot 1 \\
21 \cdot 3 \\
18 \cdot 1\end{array}$ & $\begin{array}{l}4 \cdot 4 \cdot 3 \\
5 \cdot 3 \cdot 4 \\
5 \cdot 5 \cdot 3 \\
3 \cdot 4 \cdot 3 \\
5 \cdot 4 \cdot 4\end{array}$ & 垫 \\
\hline $\begin{array}{l}\mathrm{C} R 1221 \\
\mathrm{O} R 1222 \\
\mathrm{CR} 1223\end{array}$ & $\mathrm{Zr}_{\mathbf{r}}$ & $\begin{array}{l}0 \cdot 1 \\
0 \cdot 2 \\
0 \cdot 5\end{array}$ & $\begin{array}{l}40 \\
35 \\
25\end{array}$ & $\begin{array}{l}\text { 細かい粒狀パーライト殘存 } \\
\text { 同 } \quad \text { 上 } \\
\text { 同 }\end{array}$ & $\begin{array}{l}10 \cdot 5 \\
11 \cdot 8 \\
13 \cdot 5\end{array}$ & $\begin{array}{l}7 \cdot 7 \cdot 5 \\
4 \cdot 3 \cdot 4 \\
3 \cdot 3 \cdot 2\end{array}$ & 盐 \\
\hline $\begin{array}{l}\text { C R } 1061 \\
\text { C R } 1062 \\
\text { C R } 1063 \\
\text { C R } 1064 \\
\text { C R } 1065\end{array}$ & Sn & $\begin{array}{l}0 \cdot 1 \\
0 \cdot 2 \\
0 \cdot 5 \\
1 \cdot 0 \\
1 \cdot 5\end{array}$ & $\begin{array}{l}40 \\
40 \\
40 \\
45 \\
45\end{array}$ & 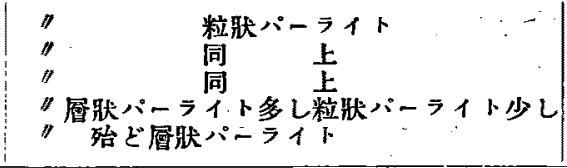 & $\begin{array}{l}8 \cdot 3 \\
7 \cdot 6 \\
7 \cdot 1 \\
6 \cdot 2 \\
6 \cdot 5\end{array}$ & $\begin{array}{l}8 \cdot 8 \cdot 7 \\
5 \cdot 6 \cdot 6 \\
5 \cdot 7 \cdot 5 \\
7 \cdot 7 \cdot 5 \\
7 \cdot 6 \cdot 6\end{array}$ & $\begin{array}{l}\text { 熄 } \\
" \prime \\
" 1 \\
"\end{array}$ \\
\hline $\begin{array}{l}\text { C R } 1191 \\
\text { C R } 1192 \\
\text { C R } 1193 \\
\text { C R } 1194\end{array}$ & $\mathrm{~Pb}$ & $\begin{array}{l}0 \cdot 05 \\
0 \cdot 10 \\
0 \cdot 30 \\
0 \cdot 70\end{array}$ & $\begin{array}{l}45 \\
45 \\
45 \\
45\end{array}$ & 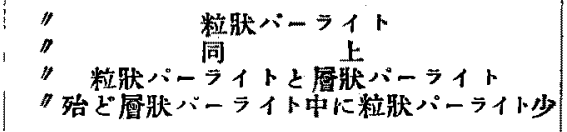 & $\begin{array}{r}10 \cdot 3 \\
10 \cdot 3 \\
15 \cdot 3 \\
8 \cdot 7\end{array}$ & $\begin{array}{l}7 \cdot 8 \cdot 7 \\
7 \cdot 6 \cdot 6 \\
6 \cdot 4 \cdot 5 \\
7 \cdot 7 \cdot 8\end{array}$ & 境 \\
\hline
\end{tabular}




\begin{tabular}{|c|c|c|c|c|c|c|c|}
\hline $\begin{array}{l}\text { C R } 1171 \\
\text { C R R172 } \\
\text { C R } 1173 \\
\text { C R } 1174\end{array}$ & $\mathbf{P}$ & $\begin{array}{l}0 \cdot 05 \\
0 \cdot 10 \\
0 \cdot 20 \\
0 \cdot 30\end{array}$ & $\begin{array}{l}35 \\
35 \\
25 \\
25\end{array}$ & 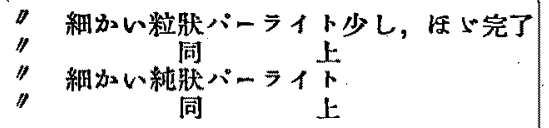 & $\begin{array}{r}7 \cdot 7 \\
13 \cdot 2 \\
11 \cdot 9 \\
20 \cdot 4\end{array}$ & $\begin{array}{l}7 \cdot 5 \cdot 5 \\
6 \cdot 5 \cdot 7 \\
5 \cdot 6 \cdot 6 \\
3 \cdot 2 \cdot 9\end{array}$ & - 塊 \\
\hline $\begin{array}{l}\text { O R } 1051 \\
\text { C R } 1052 \\
\text { C R } 1053 \\
\text { C R } 1054 \\
\text { C R } 1055\end{array}$ & $V$ & $\begin{array}{l}0.05 \\
0.10 \\
0.20 \\
0.30 \\
0.50\end{array}$ & $\begin{array}{r}40 \\
45 \\
45 \\
50 \\
60\end{array}$ & 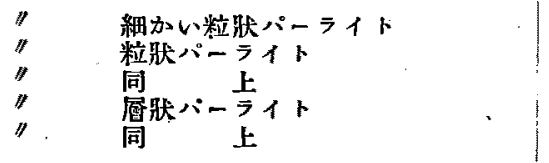 & $\begin{array}{l}10 \cdot 7 \\
10 \cdot 5 \\
15 \cdot 2 \\
13 \cdot 2 \\
10 \cdot 1\end{array}$ & $\begin{array}{l}6 \cdot 7 \cdot 5 \\
6 \cdot 7 \cdot 5 \\
5 \cdot 5 \cdot 6 \\
4 \cdot 5 \cdot 4 \\
6 \cdot 5 \cdot 8\end{array}$ & 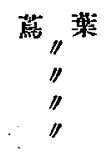 \\
\hline $\begin{array}{l}\text { C R1121 } \\
\text { CR R1122 } \\
\text { C R1123 } \\
\text { C R1124 }\end{array}$ & $\mathrm{Sb}$ & $\begin{array}{l}0 \cdot 05 \\
0 \cdot 10 \\
0 \cdot 20 \\
0 \cdot 30\end{array}$ & $\begin{array}{l}45 \\
45 \\
55 \\
50\end{array}$ & 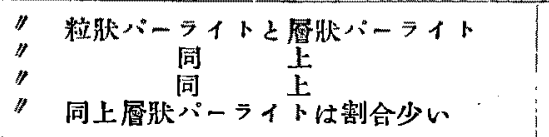 & $\begin{array}{r}8 \cdot 7 \\
9 \cdot 1 \\
10 \cdot 3 \\
9 \cdot 3\end{array}$ & $\begin{array}{l}8 \cdot 7 \cdot 7 \\
7 \cdot 5 \cdot 5 \\
6 \cdot 7 \cdot 5 \\
7 \cdot 5 \cdot 5\end{array}$ & 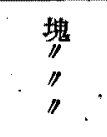 \\
\hline $\begin{array}{l}\text { C R } 1111 \\
\text { C R } 1112 \\
\text { C R } 1113 \\
\text { C R } 1114\end{array}$ & $\mathrm{Bi}$ & $\begin{array}{l}0 \cdot 20 \\
0 \cdot 50 \\
1 \cdot 00 \\
1 \cdot 50\end{array}$ & $\begin{array}{l}35 \\
25 \\
35 \\
25\end{array}$ & 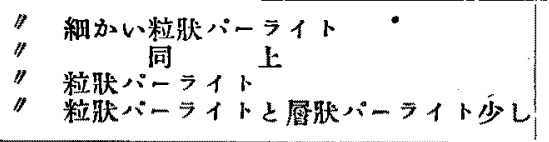 & $\begin{array}{l}10 \cdot 9 \\
12 \cdot 3 \\
14 \cdot 5 \\
16 \cdot 2\end{array}$ & $\begin{array}{l}8 \cdot 7 \cdot 7 \\
7 \cdot 6 \cdot 7 \\
5 \cdot 6 \cdot 6 \\
4 \cdot 5 \cdot 5\end{array}$ & $\begin{array}{l}\text { 幫 } \\
" 1 " \\
\text { " }\end{array}$ \\
\hline $\begin{array}{l}\text { C R1151 } \\
\text { C R I152 } \\
\text { C R I153 } \\
\text { C R } 1154\end{array}$ & $\mathbf{S}$ & $\begin{array}{l}0 \cdot 05 \\
0 \cdot 10 \\
0 \cdot 30 \\
0 \cdot 50\end{array}$ & $\begin{array}{l}40 \\
40 \\
45 \\
50\end{array}$ & 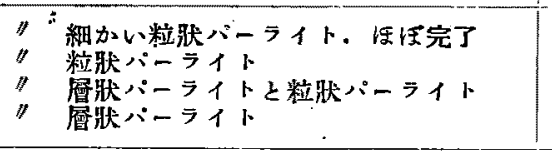 & $\begin{array}{l}18 \cdot 1 \\
12 \cdot 1 \\
26 \cdot 7 \\
25 \cdot 3\end{array}$ & $\begin{array}{l}5 \cdot 4 \cdot 4 \\
6 \cdot 5 \cdot 4 \\
2 \cdot 2 \cdot 2 \\
2 \cdot 2 \cdot 3\end{array}$ & $\begin{array}{l}\text { 瑰 } \\
\text { 球 } \\
\text { " }\end{array}$ \\
\hline $\begin{array}{l}\text { C R } 1201 \\
\text { C R } 1202 \\
\text { CR } 1203 \\
\text { C R } 1204\end{array}$ & Mo & $\begin{array}{l}0 \cdot 1 \\
0 \cdot 3 \\
0 \cdot 7 \\
1 \cdot 0\end{array}$ & $\begin{array}{l}45 \\
50 \\
50 \\
50\end{array}$ & 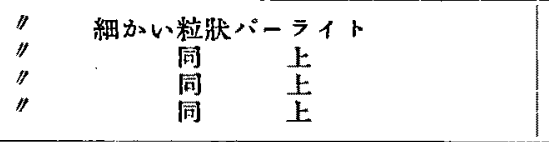 & $\begin{array}{r}13 \cdot 3 \\
13 \cdot 1 \\
10 \cdot 6 \\
6 \cdot 7\end{array}$ & $\begin{array}{l}2 \cdot 3 \cdot 3 \\
3 \cdot 2 \cdot 3 \\
3 \cdot 3 \cdot 4 \\
4 \cdot 3 \cdot 2\end{array}$ & 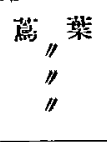 \\
\hline $\begin{array}{l}\text { CR1211 } \\
\text { CR1212 } \\
\text { CR } 1213 \\
\text { C R } 1214\end{array}$ & $\mathbf{W}$ & $\begin{array}{l}0 \cdot 1 \\
0 \cdot 3 \\
0 \cdot 7 \\
1 \cdot 0\end{array}$ & $\begin{array}{l}45 \\
45 \\
45 \\
50\end{array}$ & 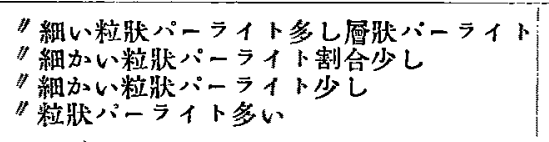 & $\begin{array}{r}7 \cdot 1 \\
11 \cdot 1 \\
9 \cdot 7 \\
8 \cdot 3\end{array}$ & $\begin{array}{l}6 \cdot 5 \cdot 6 \\
4 \cdot 5 \cdot 5 \\
\mathbf{3} \cdot \mathbf{4} \cdot 4 \\
4 \cdot 6 \cdot 7\end{array}$ & $\begin{array}{l}\text { 瑰 } \\
\text { "” } \\
" 1\end{array}$ \\
\hline $\begin{array}{l}\text { CRI141 } \\
\mathrm{OR} 1142 \\
\mathrm{CR} \operatorname{R} 143 \\
\mathrm{C} \operatorname{Rl144}\end{array}$ & $\mathrm{Co}$ & $\begin{array}{l}0 \cdot 2 \\
0 \cdot 5 \\
1 \cdot 0 \\
1 \cdot 5\end{array}$ & $\begin{array}{l}40 \\
35 \\
25 \\
25\end{array}$ & 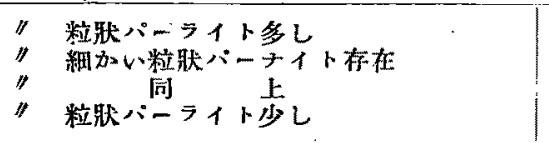 & $\begin{array}{l}20 \cdot 3 \\
30 \cdot 6 \\
\mathbf{3 5 \cdot 1} \\
\mathbf{3 5 \cdot 9}\end{array}$ & $\begin{array}{l}1 \cdot 1 \cdot 2 \\
2 \cdot 3 \cdot 2 \\
2 \cdot 2 \cdot 2 \\
2 \cdot 2 \cdot 1\end{array}$ & 㱱 \\
\hline $\begin{array}{l}\text { C R1091 } \\
\text { C R1092 } \\
\text { C R1093 } \\
\text { C R1094 }\end{array}$ & $\mathrm{Ni}$ & $\begin{array}{l}0 \cdot 2 \\
0 \cdot 5 \\
1 \cdot 0 \\
1 \cdot 5\end{array}$ & $\begin{array}{l}40 \\
35 \\
30 \\
25\end{array}$ & 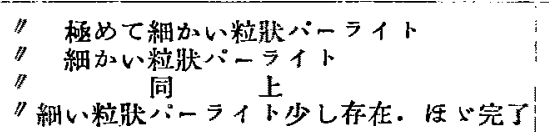 & $\begin{array}{l}14 \cdot 4 \\
19 \cdot 3 \\
20 \cdot 6 \\
21 \cdot 3\end{array}$ & $\begin{array}{l}5 \cdot 5 \cdot 7 \\
4 \cdot 5 \cdot 5 \\
5 \cdot 4 \cdot 3 \\
4 \cdot 3 \cdot 2\end{array}$ & $\begin{array}{l}\text { 塊 } \\
\text { " } \\
\text { " }\end{array}$ \\
\hline
\end{tabular}

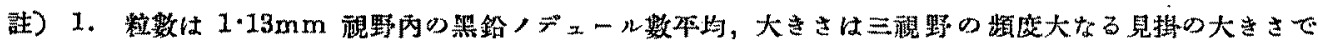
單位は $0.0138 \mathrm{~mm}$ でる。

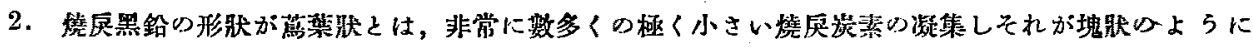
かたまつていないものを言ら。

\section{IV. 合金元素の影琶}

Na：Naは一般に焟戻炭素が大きく第一段終了後のプ ルナイ組織も比教的大きい，源加量加增すにつれて第一 段黒鈶化に好影望を与えるが，第二段黒鈶化には余り影 势がない。

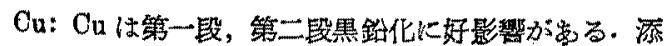
加により焼送黑鉿は嚾か小さくなる、源加量の多いる。 は $200 \mathrm{hr}$ 焼釿て完全に第二段黑鈶化が完了した.

Mg: Mg は黑鉻化には著しい影覀はない. 注目すべ

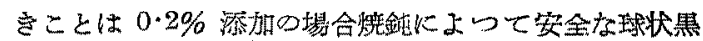

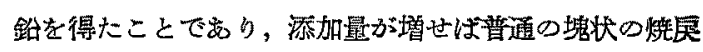
宸絜状になる。

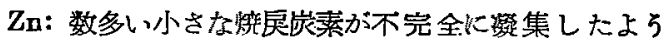

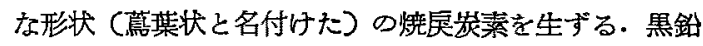
化には殆に゙影響なく，第二段黒鈶化では蜜ろ阻害の傾间 放数公。

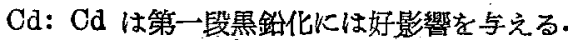

B：添加量が大になるにつれて第一段黑敛化に悪影炤 がをる. 極少量添加の場合には脱酸効果により黒鉛化を 


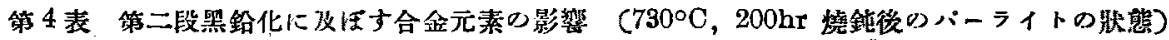

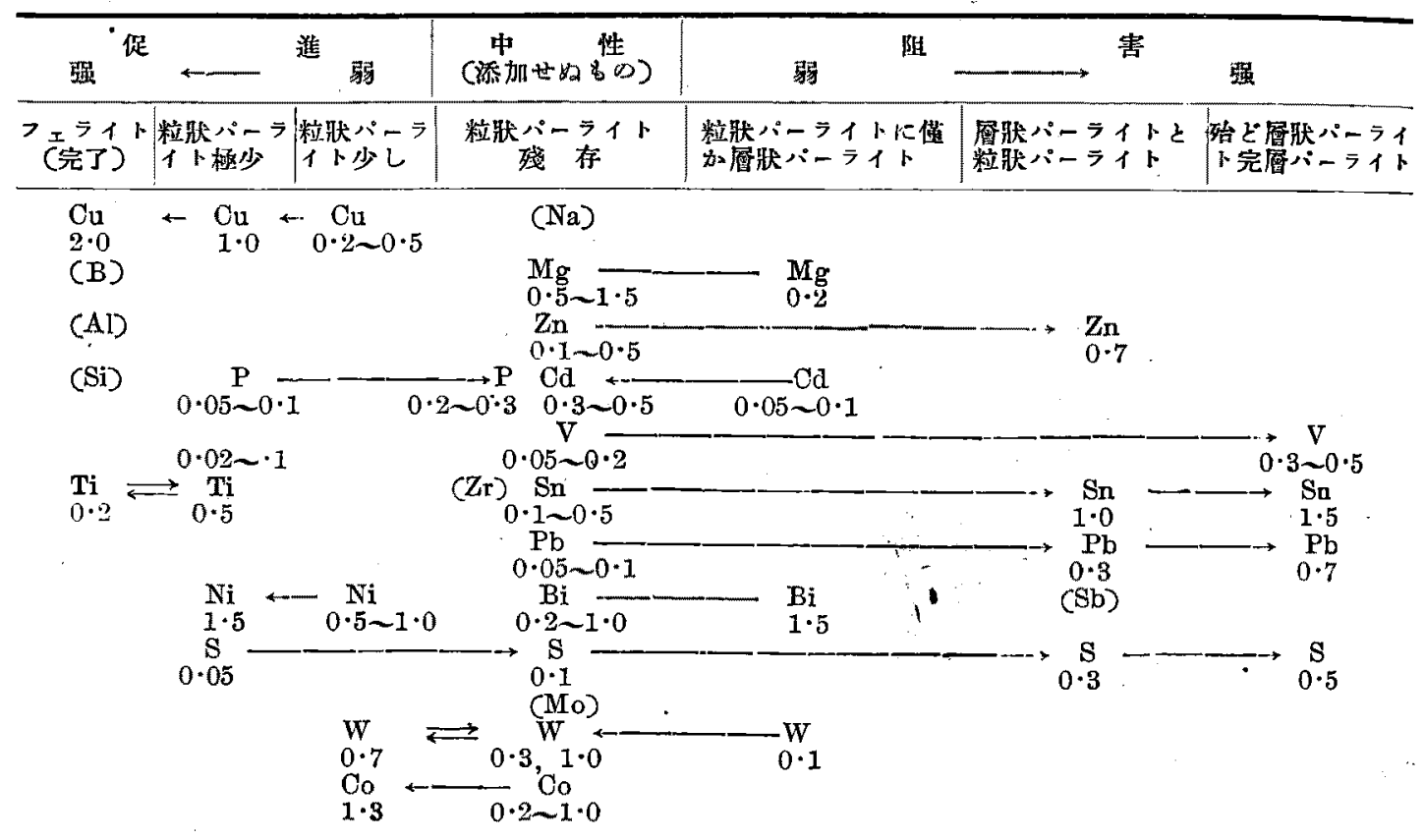

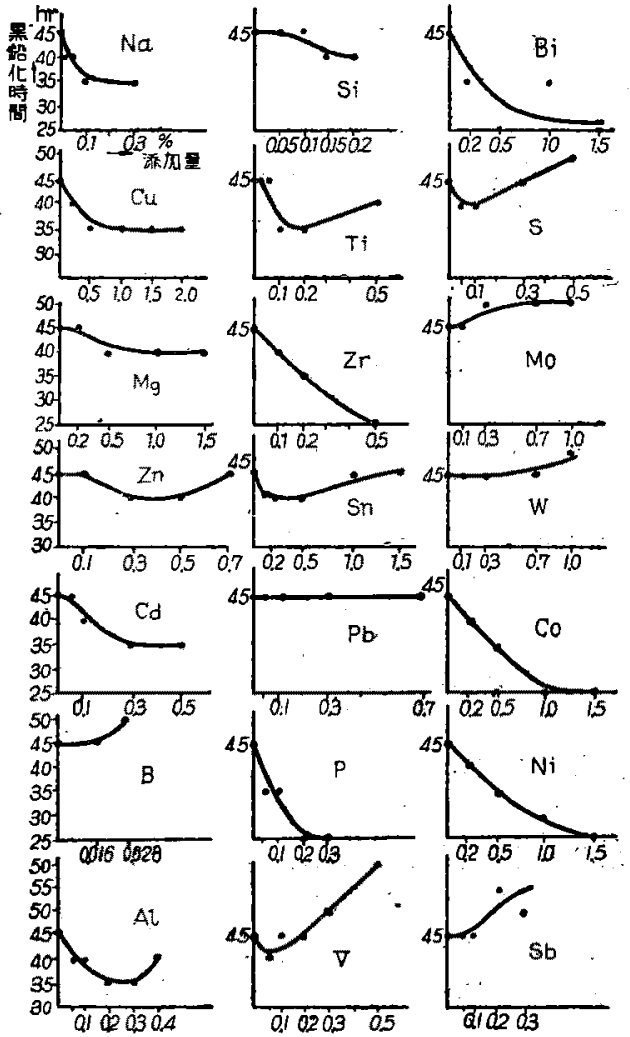

第 2 圆 第一段黑鉿化洔閒に之ほ寸各種合金元素の影警

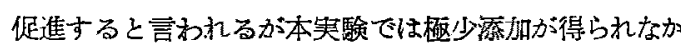
つた，第二段黒鈶化には踑る好効果があり $145 \mathrm{hr}$ で完 了した・これは著しく数多い細かな粒忋の烧戻炭素に原 因するものと思われる。

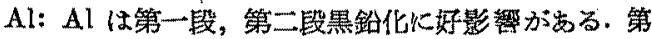
二段は添加少きものは $200 \mathrm{hr}$, 添加量增すにつれて 165 hr 完了した，但し添加量が多くなると初析黒鉾を生す

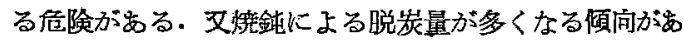
る. 焼联炭素は細かくなり良く疑集しない。

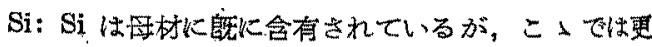
に潦加した量に就いて論じてま苟。湑加は黑鉛化を第一

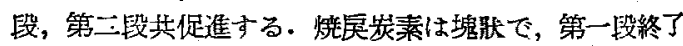

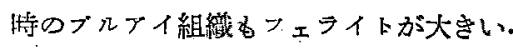

Ti：Ti は $0.1 \sim 0.2 \%$ 源加のるのが好影響である.

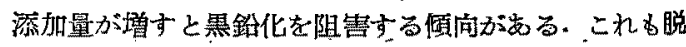

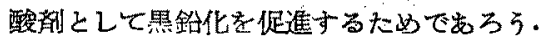

フェロチタ、は Al を含有しているから Al と Ti の両

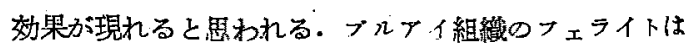
大きい.

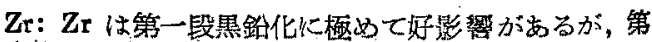

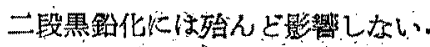

Sn：少量の添加交余り影響がないが，潦加量が增す と第二段黒鈶化火特火惠影響がある・捇戻炭素は大きく 


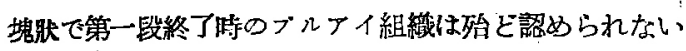
程度て市る。

$\mathrm{Pb}: \mathrm{Pb}$ は第一段には全く影䅉がながたが，第二段

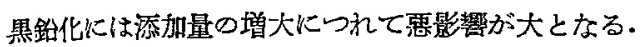

P: P は第一段黒鈶化に極女て好效果が女る。

$\mathrm{V}: \mathrm{V}$ は第一弫，第二段共に頻る悪影響があり，0.5

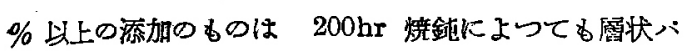
ーライトは全然分蟹していない.

$\mathrm{Sb}: \mathrm{Sb}$ 第一段，第二段共に恵影餢を与える・ブル フイ組䋘は殆ど認められない。

$\mathrm{Bi}$ ：第一段黒鈶化には極めて促進効果があるが，第

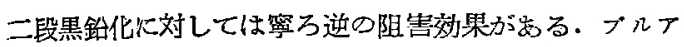

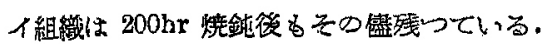

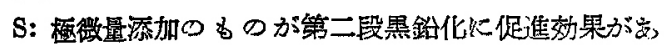
つたがこれは Mn と S の平衖より過剩の Mnの阻器 影響をこれが㧕えたるのでるる. 采知の如く源加量の増 大により著しい阻害影㥜が安り，殊火第二段に於いては バーライトは全く分解しなくなら. 0.5\% 源加のるのは 球状黒鉛鋳鉄比ずるような完全な球状黒鉛で，その見 脚の大きさがこれを生ずることにより急隹小さくなる.

Mo：第一段，第二段共に弱い阻害糼果が范る。

W: Mo：と大体同影得がある.

Co: Co は第一段黒鉛化を著しく促進する．焙戻炭絜

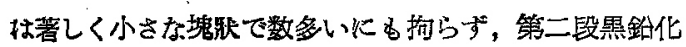
には殆んビ影饗がない。

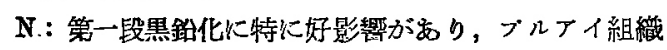
のフェライト地が著しく多くなる.第二臣黑鈶化にも弱 ，日促進効果がある。

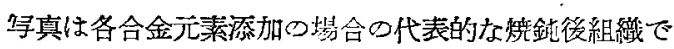

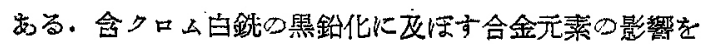

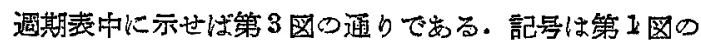
墇合と同様で記昂の修の数字は1は第一，2は第二段黑 鈶化に於てのみその記号の影留が現れたことを示す。

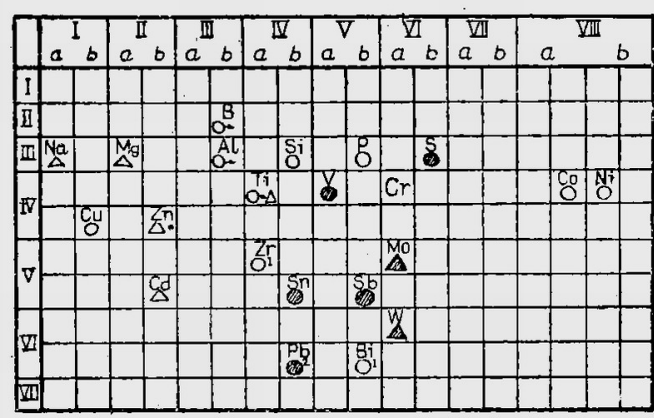

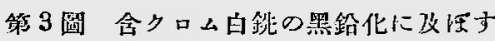
合金元冞の影蚃

\section{V. 結 論}

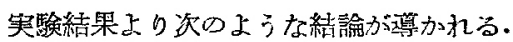

1) $0 \cdot 156 \%$ 程度の $\mathrm{Cr}$ を含む白銑の黑鉛化们し て特に著しく黒鉛化を媅展し，Or の卧を除いたものは なからた。

2) $\mathrm{Al}, \mathrm{Si}, \mathrm{Ti}, \mathrm{Cu}, \mathrm{B}$ (第二段

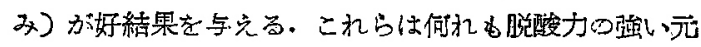

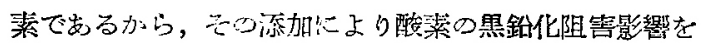

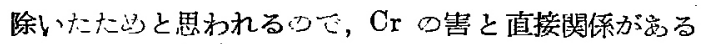
か否かは今の所判らない。

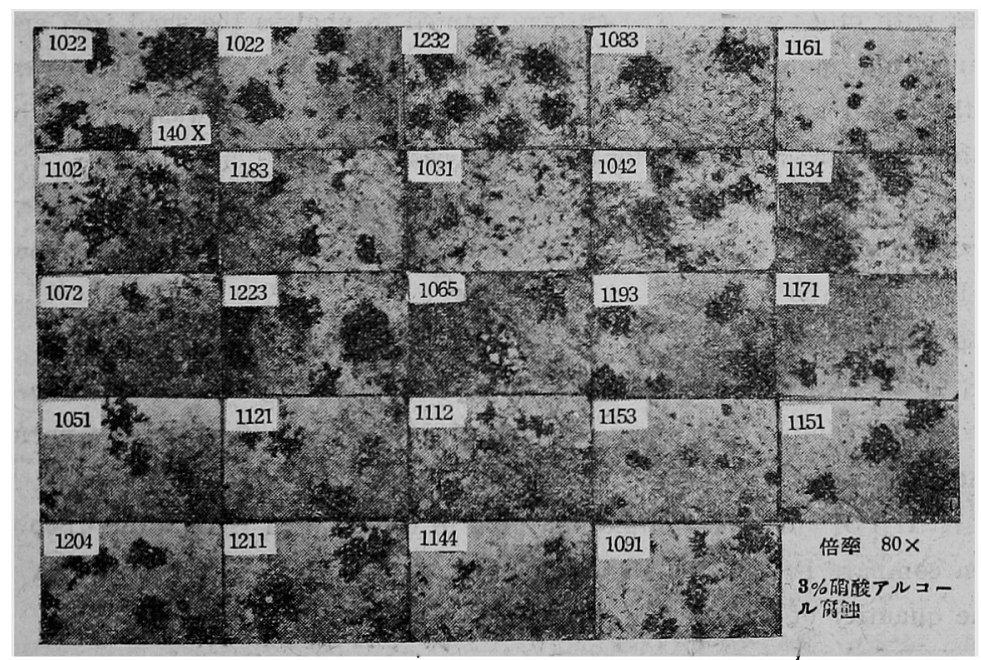

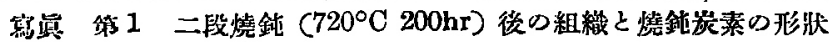


9) $\mathrm{Oo}, \mathrm{Ni}, \mathrm{Bi}$ 及び $\mathrm{P}$ は特に第一段黑鈶化に好影響

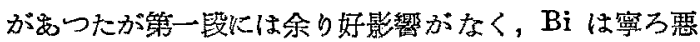

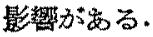

4) 著しく阻害効果を与兄た元素は $\mathrm{Sn}, \mathrm{V}, \mathrm{Sb}, \mathrm{S}$ (蒸

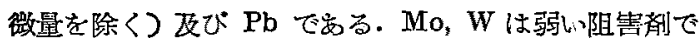
ある。

5) 過剩なS K対する Mn の如き親和力の強い救助

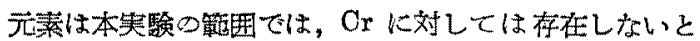
結論される。

終りに臨み本寒験に多大の助力を裁いた故藤原延生氏 と秋田卓也氏に厚く感謝致します（昭和28年 3 月寄稿) 交献

1) M. Gabriel Joly: Fondrie, April (1949) 1537

2) J. E. Rehder: Preprint of American Foun- drymen's Society Annual Meeting, 1951, Preprint No. $51 \sim 51$

3) H. A. Schwartz: Foundry Trade Journal, June 13, (1946) 162

4) E. Chüz \& R. Stotz: Der Temperguss, (1930) 74

5) P. Oberhoffer: Das technische Eisen, (1936) 560

6) F. L. Coonan: Foundry, Vol, 60, (1932) $4 \mathrm{y}$

7) S. W. Palmer: Foundry Trade Jonrnal, Oct: 9, (1947) 111, Oct. 16, (1947) 129

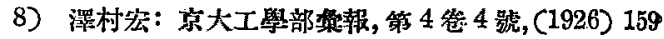

9) 菊田多利男:践と銅，第 13 年 1 號，(192) 741

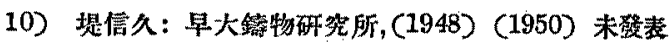

燐酸法に依る砂鐵の $\mathrm{T} . \mathrm{Fe}, \mathrm{TiO}_{2}$, 燒結鑛の

T.Fe, As の迅速分析法

森本武生* ·瀧澤英郎* ·大竹三義*

\section{RAPID ANALYSIS OF T.F $\& \mathrm{TiO}_{2}$ IN SAND IRON AND}

T.F $\&$ \& AS IN SINTER BY THE $\mathrm{H}_{3} \mathrm{PO}_{4}$ METHOD .

\section{Takeo Morimoto, Hideo Takizawa and Mitsuyoshi Otake}

\section{Synopsis:}

Studies \& ucilizations of sand iron has been developing in Japan. There are many sand iron. sources in Hokkaido. Therefore Muroran Iron Works has been using a larger quantity of sand i ron as compared with other works. The authors wanted to analyse the sand iron and the sinter mixed with sand iron more rapidly and more accurately. But these samples were difficult to dissolve, so the alkali melting or hydrofluoric acid melting method was applyed in which the platinum or china vessel was required for these analysis.

But it was necessary to save such long time required and to save special vessels, and many samples could not be treated in a time for such analysis. The authors found the following method. by addition of $\mathrm{H}_{3} \mathrm{PO}$, to the samples.

r. Fixing the quantity of T.Fe

Add $\mathrm{H}_{3} \mathrm{PO}_{4}$ to the sample and add a small quantity of $\mathrm{HCl}$ to oxidize it.to make $\mathrm{FeCl}_{5}$ after dissolution of the sample and then the quantity of $\mathrm{Fe}$ was fixed by the normal method.

2. Fixing the quantity of $\mathrm{TiO}_{2}$

Add $\mathrm{H}_{2} \mathrm{SO}_{4}$ \& $\mathrm{H}_{3} \mathrm{PO}_{4}$ to this sample and give to colour with $\mathrm{H}_{2} \mathrm{O}_{2}$ after dissolution of the sample and then compare it wich the standard.

3. Fixing the quantity of As

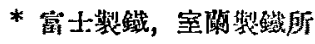

